\title{
Pendampingan Peningkatan Penjualan Bakso Ayam Endolita Pamengkang Cirebon
}

\author{
Siska Ernawati Fatimah ${ }^{1}$ \\ Univesitas Swadaya Gunung Jati Cirebon, SiskaFatimah12@gmail.com \\ Siti Maryam² \\ Univesitas Swadaya Gunung Jati Cirebon, Sitimaryam0704@gmail.com \\ Noveria Susijawati ${ }^{3}$ \\ Univesitas Swadaya Gunung Jati Cirebon, noveriasusijawati@yahoo.com
}

\begin{abstract}
Abstrak
Pemberdayaan sumber daya manusia telah dilakukan pemerintah. Hal ini sejalan dengan tujuan pembangunan Indonesia, Pemberdayaan masyarakat dalam penanggulangan kemiskinan menjadi komitmen bersama antara pemerintah pusat dengan pemerintah daerah sehingga terus berupaya untuk menggerakan Usaha Kecil, Salah satu cara menggerakan usaha kecil dengan melakukan pendampingan sampai dengan pelatihan terhadap para pelaku usaha kecil. Salah satu Usaha kecil di Kota Cirebon bergerak dalam bidang pembuatan Bakso Ayam, salah satunya Bakso Ayam Endolita yang berada di Pamengkang Cirebon, dimana sedang menghadapi kesulitan dalam hal membuat variasi produk bakso dan cara pengemasan produknya. Kendala utama yang dihadapi adalah belum adanya variasi dari bakso ayam yang dijual karena keterbatasan pengetahuan dan belum tersedianya alat yang menunjang untuk pengemasan yang lebih baik. Tujuan dari program ini adalah memberikan edukasi pengetahuan mengenai variasi dari produk bakso ayam agar penjualan bakso lebih bervariasi lagi dan memberikan bantuan berupa alat untuk menunjang pengemasan bakso agar tampil lebih menarik, sehingga mampu bersaing dan diharapkan ke depannya mampu menambah pangsa pasar yang telah ada sekarang. Kegiatan pemberdayaan usaha kecil dilaksanakan dalam kurun waktu 2 bulan yaitu dari bulan Oktober 2019 - Februari 2020. Lokasi kegiatan dilaksanakan di Bumi Cirebon Adipura Pamengkang Cirebon. Metode pemberdayaan masyarakat yang digunakan dalam kegiatan ini adalah Participation Learning and action (PLA). Hasil yang didapatkan setelah dilaksanakan kegiatan pemberdayaan usaha kecil yaitu: 1) Pelaku usaha mampu membuat dan menambah variasi produk Bakso Ayam, 2) mampu menggunakan alat bantu pengemasan bakso ayam, 3) Mampu mengemas Bakso Ayam menjadi lebih menarik dari sebelumnya.
\end{abstract}

Kata Kunci: peningkatan penjualan, variasi produk, kemasan

Abstract

Human resource empowerment has been undertaken by the Government. This is in line with Indonesia's development goals, community empowerment in poverty alleviation become a joint commitment between the central government and the local governments so as to strive to move 
the small business, one way Small business by mentoring up to the training of small business actors. One small business in the city of Cirebon engaged in the manufacture of chicken meatballs, one of which is Bakso Ayam Endolita in Pamengkang Cirebon, where it is facing difficulties in making variations of meatballs products and how to packing the product. The main obstacle faced is the absence of variations of chicken meatballs sold because of limited knowledge and unavailability of tools that support for better packaging. The purpose of this program is to educate the knowledge of chicken meatballs products to make the sale of meatballs more varied and provide assistance in the form of tools to support the packaging of meatballs to appear more attractive, so able to Competing and expected in the future is able to add to the market share that has existed now. Small business empowerment activities are implemented within 2 months from October 2019-February 2020. The location of the activities was held at Bumi Cirebon Adipura Pamengkang Cirebon. The method of community empowerment used in this activity is Participation Learning and action (PLA). Results obtained after the empowerment of small business activities are: 1) Business actors are able to make and add a variety of products chicken meatballs, 2) able to use packaging aids chicken meatballs, 3) able to pack chicken meatballs become more attractive From before.

\section{Keywords : Increase in sales, product variations, packaging}

\section{Pendahuluan}

Program pemberdayaan sumber daya manusia telah dilakukan pemerintah. Hal ini sejalan dengan tujuan pembangunan Indonesia yaitu membangun manusia Indonesia seutuhnya, maka pembangunan harus merupakan perubahan sosial yang tidak hanya terjadi pada taraf kehidupan masyarakat belaka tetapi juga pada peranan unsur-unsur didalamnya. Pembangunan menempatkan manusia sebagai subyek pembangunan. Pemberdayaan masyarakat dalam penanggulangan kemiskinan menjadi komitmen bersama antara pemerintah pusat dengan pemerintah daerah. (Sedyastuti, 2018)

Pemberdayaan masyarakat adalah upaya untuk memberikan daya (empowerment) atau penguatan (strengthening) kepada masyarakat. Pemberdayaan masyarakat juga diartikan sebagai kemampuan individu yang bersenyawa dengan masyarakat dalam membangun keberdayaan masyarakat yang bersangkutan sehingga bertujuan untuk menemukan alternatif-alternatif baru dalam pembangunan masyarakat (Totok \& Poerwoko Soebiato, 2019). Pemberdayaan akan berhasil jika dilakukan secara terstruktur dengan membangun budaya kerja yang baik. Konsep pemberdayaan terkait dengan pengertian pembangunan masyatakat dan pembangunan yang bertumpu pada masyarakat sehingga diharapkan dapat mengatasi kemiskinan (Lena Satlita, 2017).

Kemiskinan merupakan masalah pembangunan kesejahteraan sosial yang berkaitan dengan berbagai bidang pembangunan lainnya yang ditandai oleh pengangguran, keterbelakangan, dan ketidakberdayaan. Oleh karena itu, kemiskinan merupakan masalah pokok nasional yang penanggulanggannya tidak dapat ditunda lagi dan harus menjadi prioritas utama dalam pelaksanaan pembangunan kesejahteraan sosial. (Setiawan, 2017)

Penanganan kemiskinan tidaklah mudah, karena telah mengalami masalah kemiskinan yang berlangsung lama. Masyarakat menengah kebawah mengalami 
keterbatasan dalam hal pendidikan, keterampilan, sarana usaha, serta modal usaha, sehingga banyak yang melakukan usaha kecil seperti berdagang yang diharapkan dapat membantu mengatasi kemiskinan. Usaha kecil sebagian banyak dilakukan oleh wanita. (Ni Wayan Suarmini, Siti Zahrok, 2018) Wanita bukan saja dianggap pelengkap keluarga pada saat ini, tetapi wanita sebagai partner pria dalam membangun rumah tangga. Hal ini yang membuat wanita terpanggil untuk ikut berperan membantu perekonomian keluarganya.(Indiworo, 2017)

Salah satu wanita yang melakukan usaha kecil di Kota Cirebon salah satunya adalah Ibu Tini. Kami tertarik dengan usaha kecil Ibu Tini yaitu Bakso Ayam Endolita, dimana usaha tersebut telah berjalan lama sekitar 2 tahun penjualan bakso ayam tersebut hanya mampu menutupi biaya produksi. Penjualan bakso ayam yang kursng meningkat disebabkan salah satunya adalah kurang menarik baik dari segi variasi produk maupun kemasannya. Sehingga kami sangat tertarik untuk meningkatkan penjualan Bakso Ayam Endolita. Variasi produk adalah sebagai bauran produk yang disebut juga dengan pilihan produk adalah kumpulan semua produk dan barang yang ditawarkan dan dijual oleh penjual tertentu. (Efnita, 2017) Pengemasan adalah aktivitas merancang dan memproduksi kemasan atau pembungkus untuk produk. Biasanya fungsi utama dari kemasan adalah untuk menjaga produk. (Sayatman, Ramadhani, \& Alamin, 2018) Namun, sekarang kemasan menjadi faktor yang cukup penting sebagai alat pemasaran agar dapat menarik konsumen dalam meningkatkan penjualan dan memberikan kepuasan kepada konsumen secara maksimal.(A. Azis Said, 2016) Bakso merupakan makanan yang sangat digemari oleh masyarakat Indonesia, salah satunya adalah Bakso Ayam. Dari hasil pengamatan terdapat beberapa permasalahan oleh Bakso Ayam Endolita, yaitu:

1. Minimnya pengetahuan dan inovasi serta kompetensi kewirausahaan pelaku usaha yang mengakibatkan rendahnya produktivitas usaha. Hal tersebut juga tampak pada ketidakmampuan pelaku dalam hal membuat variasi Bakso Ayam.

2. Pelaku Usaha juga masih menghadapi kendala dalam hal akses pendanaan modal. Akibatnya, pelaku kesulitan dalam meningkatkan kapasitas usahanya atau mengembangkan produk-produk yang mampu bersaing. Hal ini tampak dalam pengemasan produk Bakso Ayam yang masih sangat sederhana.

Berikut ini dokumentasi kegiatan survei kepada mitra Program Kemitraan Masyarakat.

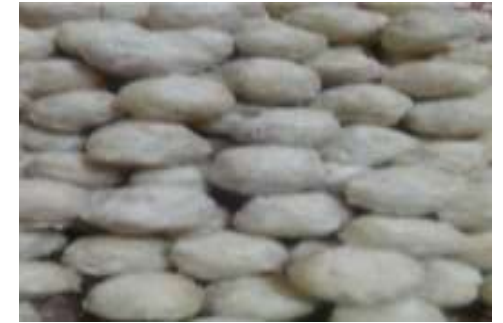

Gambar 1. Produk Sekarang

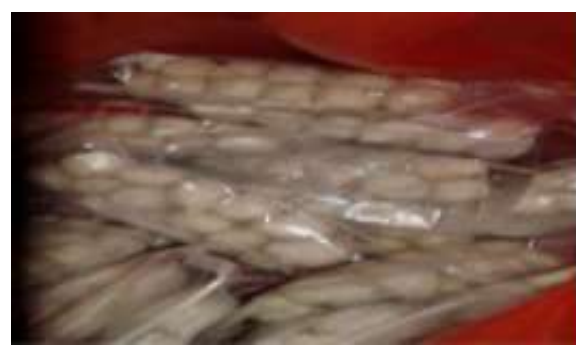

Gambar 2. Kemasan sekarang 
Pendampingan Kewirausahaan bagi Bakso Ayam Endolita, bertujuan agar tetap bertahan dan berhasil secara berkelanjutan dalam menjalankan usaha. Adapun tujuan yang lebih rinci dari program ini adalah:

- Memberikan pengetahuan dan keterampilan kepada pelaku usaha Bakso Ayam Endolita mengenai beragam variasi Bakso Ayam Endolita

- Memberikan alat bantu berupa alat press vaccum plastik dan alat press plastik serta plastik khusus press untuk meningkatkan kemasan Bakso Ayam Endolita, serta memberikan keterampilan kepada pelaku Bakso Ayam Endolita untuk menggunakan alat tersebut

Maksud diadakannya pendampingan pada usaha kecil Bakso Ayam Endolita dari program ini adalah:

- Pemilik Bakso Ayam memperoleh memiliki pengetahuan mengenai varian bakso ayam sehingga diharapkan mampu membuat variasi dari bakso ayam yang sudah ada saat ini

- Pemilik Bakso Ayam dengan adanaya bantuan alat dalam proses pengemasan diharapkan agar dapat meningkatkan kemasan bakso ayam lebih menarik dari yang sudah ada saat ini sehingga adanya peningkatan penjualan

Penjual yang menawarkan banyaknya pilihan produk yang ditawarkan kepada konsumen dengan kemasan yang dirancang dengan baik dapat membangun ekuitas merek dan meningkatkan penjualan (A. Azis Said, 2016). Sehingga diharapkan dapat menarik pembeli dan konsumen dapat dengan leluasa memilih berbagai alternatif pilihan produk yang ditawarkan. Dari banyaknya pilihan variasi produk dan kemasan yang menarik diharapkan dapat meningkatkan penjualan dan merambah pangsa pasar dari yang sudah ada sekarang.(Mufreni, 2016)

\section{Metode}

Pelaksanaan pengabdian kepada masyarakat oleh Tim Pengabidan dilaksanakan sebagai berikut:

Tabel 1. Indikator Pencapaian Tujuan Varian Produk

\begin{tabular}{|c|c|c|c|}
\hline No & Kegiatan & Waktu & Tempat \\
\hline 1 & $\begin{array}{l}\text { Observasi usaha kecil Bakso Ayam Endolita } \\
\text { oleh Tim }\end{array}$ & 20 Oktober 2019 & $\begin{array}{l}\text { Bumi Cirebon } \\
\text { Adipura } \\
\text { Pamengkang }\end{array}$ \\
\hline 2 & $\begin{array}{l}\text { Koordinasi dengan Kepada } \\
\text { Pamengkang Kota Cirebon }\end{array}$ & 02 Desember 2019 & $\begin{array}{l}\text { Kantor Desa } \\
\text { Pamengkang }\end{array}$ \\
\hline 3 & $\begin{array}{l}\text { Terjun Langsung untuk mengetahui } \\
\text { permasalahan yang dihadapi oleh pelaku } \\
\text { usaha Bakso Ayam Endolita }\end{array}$ & $\begin{array}{l}10-15 \quad \text { Desember } \\
2019\end{array}$ & $\begin{array}{l}\text { Bumi Cirebon } \\
\text { Adipura } \\
\text { Pamengkang }\end{array}$ \\
\hline 4 & $\begin{array}{l}\text { Sosialisasi dengan menawarkan solusi } \\
\text { terhdap masalah yang dihadapi: } \\
\text { a. Pemberian Edukasi pengetahuan } \\
\text { mengenai variasi produk bakso ayam } \\
\text { dan kemasan produk yang menarik }\end{array}$ & 4 - 5 Januari 2020 & $\begin{array}{l}\text { Bumi Cirebon } \\
\text { Adipura } \\
\text { Pamengkang }\end{array}$ \\
\hline
\end{tabular}


sehingga dapat meningkatkan penjualan

b. Diskusi mengenai desain merk untuk kemasan bakso ayam endolita

c. Menetapkan tanggal untuk praktek bersama pembuatan variasi bakso ayam dan penggunaan alat bantu kemasan

5 Pemberian bantuan alat untuk pengemasan berupa alat press vaccum plastik dan alat press plastik serta plastik khusus press

6 Praktek bersama pembuatan variasi produk baso ayam dan praktek proses penggunaan alat untuk pengemasan bakso ayam endolita

7 Sosialisasi produk varian dan kemasan baru bakso ayam endolita di kantor kepala desa

8 Pengurusan surat keterangan telah melaksanakan kegiatan pengabdian

Penyusunan laporan dan dokumentasi kegiatan pengabdian

15 Januari 2020

20 Januari 2020

21 Januari 2020

25 Januari 2020

01 febuari

febuari 2020

27 Febuari 2020
Kantor Desa

Pamengkang

Bumi Cirebon

Adipura

Pamengkang

Kantor Desa

Pamengkang

Balai Desa

Pamengkang

20 Kampus UGJ

Kampus UGJ

\section{Hasil dan Pembahasan}

Pelaksanaan pengabdian dimulai dengan melakukaan edukasi pengetahuan kepada pelaku usaha bakso ayam endolita. Permasalahan yang terjadi pada bakso ayam endolita yaitu produk bakso ayam yang kurang bervariasi dan kemasan bakso ayam yang kurang menarik. Beberapa kegiatan yang telah terlaksana untuk memperbaiki permasalahan di bakso ayam endolita adalah sebagai berikut:

a. Variasi Produk Bakso Ayam Endolita

Awal pengerjaan kegiatan pengabdian ini berupa edukasi pengetahuan mengenai variasi yang bisa dimodifaksi oleh bakso ayam kepada pelaku usaha. Pelaksanaan kegiatan ini bisa dilihat dari gambar berikut:

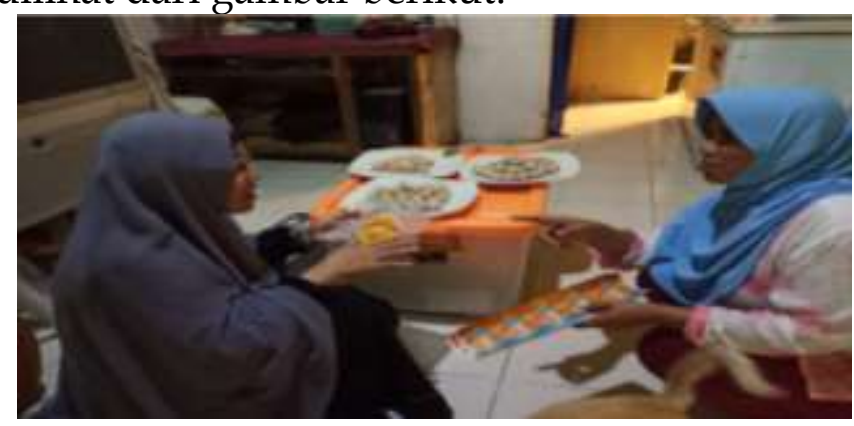

\section{Gambar 1. Edukasi Pengetahuan Varian Produk Bakso Endolita}

Setelah pemberian edukasi pengetahuan mengenai variasi bakso ayam endolita, langkash selanjutnya adalah demonstrasi bersama dari varian bakso ayam endolita. Pelaksanaan kegiatan ini bisa dilihat dari gambar berikut: 


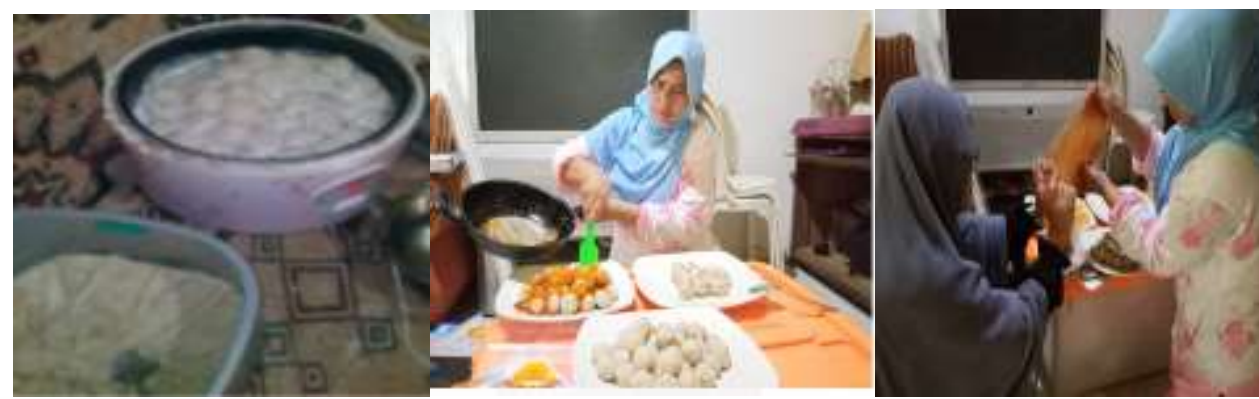

Gambar 4. Pendampingan Pembuatan Varian Produk Bakso Ayam Endolita

Dari pendampingan demonstarsi kegiatan pembuatan variasi bakso diperoleh dua variasi yang pertama bakso ayam keju dan bakso ayam saos padang. Berikut ini varisi produk yang di peroleh:

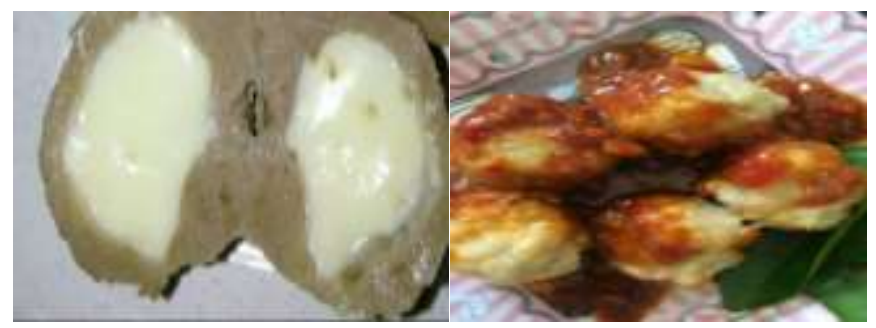

\section{Gambar 5. Varian Baru Produk Bakso Ayam Endolita}

Gambar di atas merupakan varian produk yang berhasil dikembangkan dari bakso Ayam endolita, yang semula hanya menjual bakso ayam saja kini bertambah varian dengan bakso ayam keju dan bakso ayam saos padang. Diharapkan dengan adanya penambahan dua varian tersebut konsumen dapat memilih jenis bakso ayam yang disukainya. Berikut adalah Indikator Pencapaian Tujuan sebelum dan setelah pendampingan variasi produk bakso ayam.

Tabel 1. Indikator Pencapaian Tujuan Varian Produk

\begin{tabular}{|c|c|c|}
\hline $\begin{array}{c}\text { Materi } \\
\text { Pendampingan } \\
\end{array}$ & Sebelum pendampingan & Setelah pendampingan \\
\hline $\begin{array}{l}\text { Variasi Produk } \\
\text { Bakso Ayam }\end{array}$ & $\begin{array}{l}\text { 1. Belum memahami jenis- } \\
\text { jenis varian produk bakso } \\
\text { yang dapat di inovasi } \\
\text { 2. Masih terdapat keraguan } \\
\text { akan rasa produk apabila } \\
\text { dilakukannya inovasi } \\
\text { 3. Belum mampu membuat } \\
\text { produk bakso yang } \\
\text { bervariasi }\end{array}$ & $\begin{array}{l}\text { 1. Sudah memahami jenis- } \\
\text { jenis dari varian bakso } \\
\text { yang dapat di lakukan } \\
\text { inovasi } \\
\text { 2. Hilang keraguan dan } \\
\text { lebih mantap untuk } \\
\text { membuat bermacam- } \\
\text { macam variasi dari } \\
\text { bakso ayam } \\
\text { 3. Mampu membuat } \\
\text { bakso ayam dengan } \\
\text { variasi bakso ayam keju } \\
\text { dan bakso ayam saus } \\
\text { padang }\end{array}$ \\
\hline
\end{tabular}


b. Kemasan Bakso Ayam Endolita

Tahap pengabdian selanjutnya adalah pemberian bantuan alat berupa alat press vaccum plastik dan alat press plastik serta plastik khusus press. Berikut ini pembeiran alat bantu untuk proses pengemasan bakso ayam endolita yang di saksikan oleh Kepala Desa Pamengkang Cirebon:

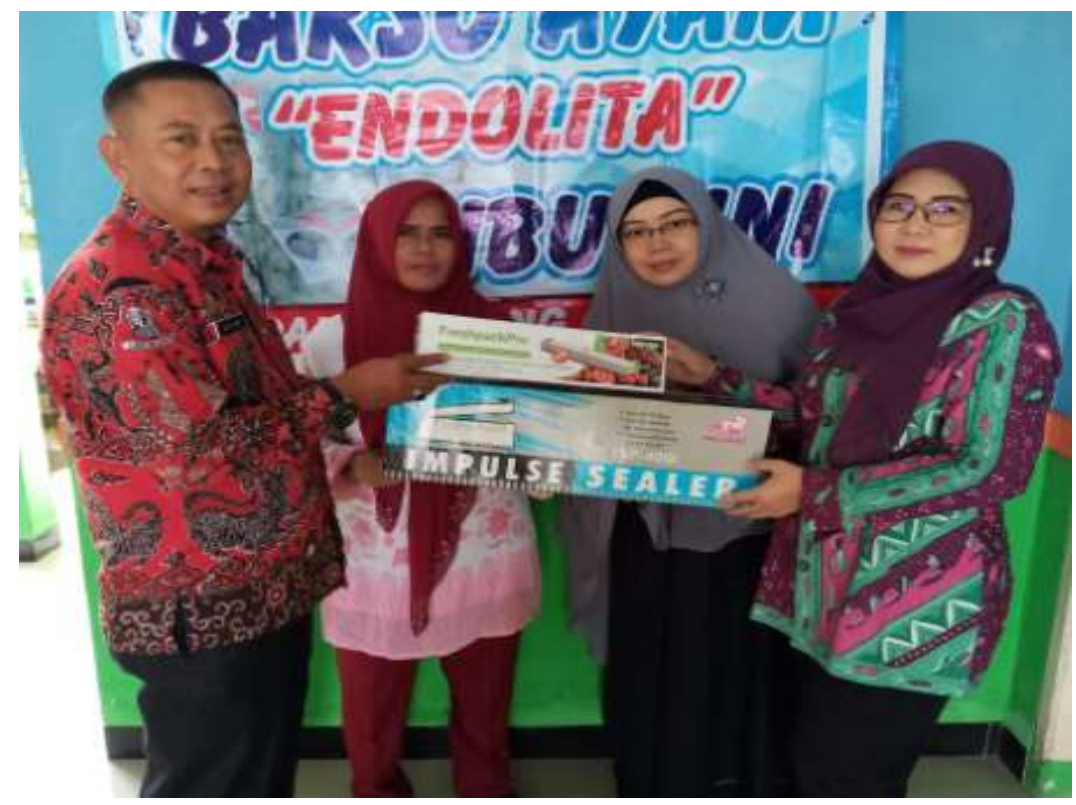

Gambar 6. Pemberian Alat Bantu Untuk Pengemasan Bakso Ayam

Setelah pemberian alat bantu untuk pengemasan bakso ayam maka dilanjutkan dengan demonstrasi penggunaan alat pengemasan yang dapat dilihat dari gambar sebagai berikut:

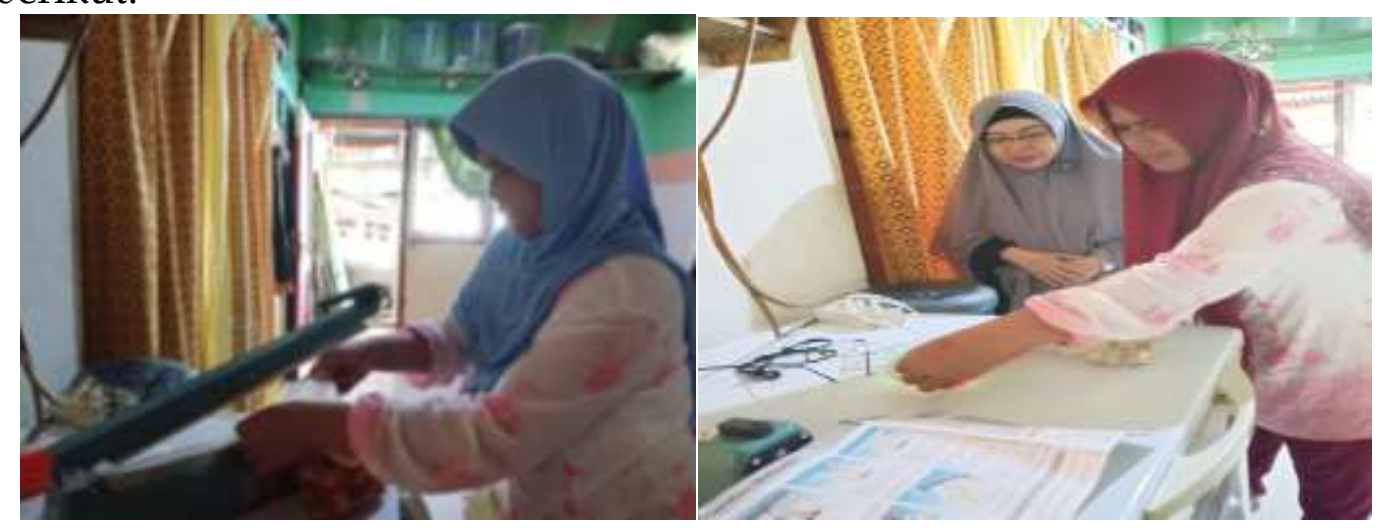

Gambar 7. Demonstrasi Penggunaan Alat Bantu Untuk Pengemasan

Setelah pelaku usaha dapat menggunakan alat bantu pengemasan untuk bakso ayam, maka pengemasan bakso ayam tampil lebih menarik, yang dapat dilihat dari gambar di bawah ini: 


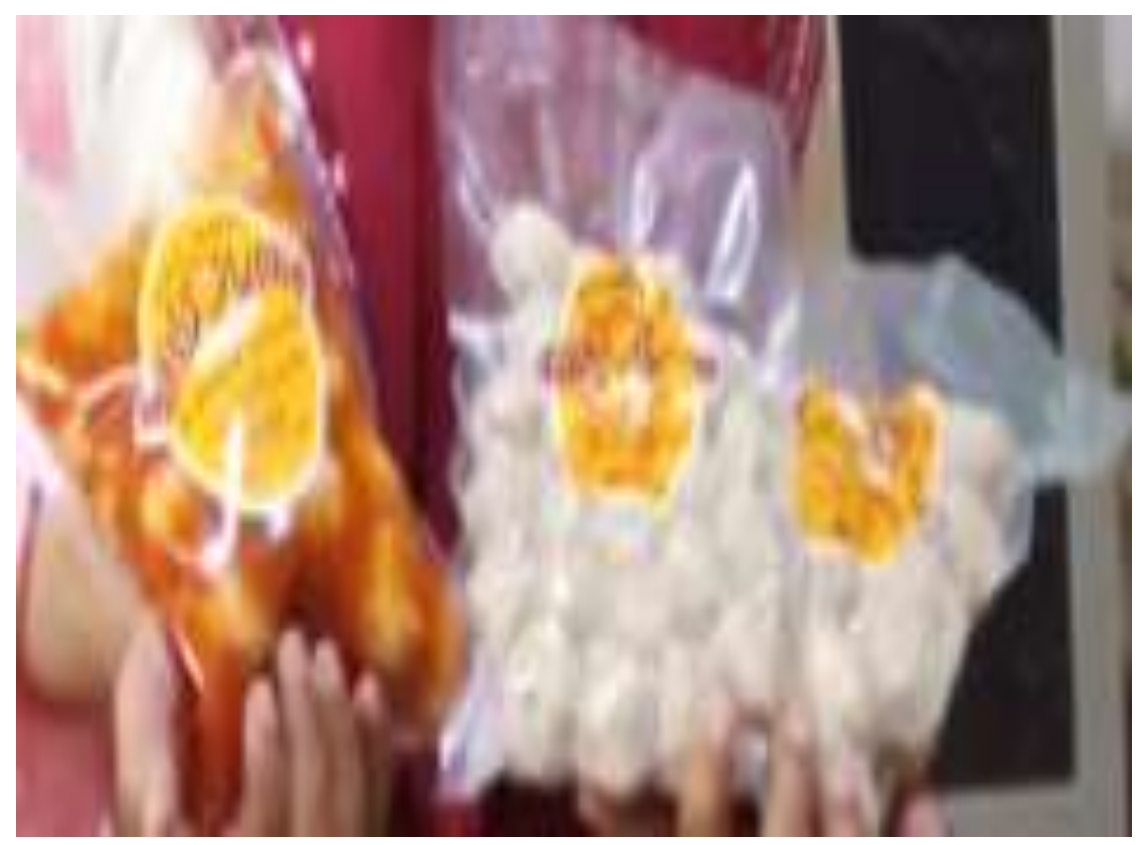

\section{Gambar 8. Kemasan Bakso Ayam Eendolita yang menggunakan merek}

Gambar 8 merupakan peningkatan kemasan Bakso Ayam Endolita yang diharapkan dapat menarik konsumen dan meningkatkan penjualan Baksio Ayam di masa yang akan datang. Berikut adalah Indikator Pencapaian Tujuan sebelum dan setelah pendampingan kemasan produk bakso ayam:

Tabel 3. Indikator Pencapaian Tujuan Kemasan Produk

\begin{tabular}{|c|c|c|}
\hline $\begin{array}{c}\text { Materi } \\
\text { Pendampingan }\end{array}$ & $\begin{array}{c}\text { Sebelum } \\
\text { pendampingan }\end{array}$ & Setelah pendampingan \\
\hline Kemasan Produk & $\begin{array}{l}\text { 1. } \begin{array}{l}\text { Belum dapat memakai } \\
\text { alat press vaccum plastik } \\
\text { dan alat press plastik }\end{array} \\
\text { 2. Menggunakan plastik } \\
\text { biasa untuk pembungkus } \\
\text { bakso ayam tanpa merek } \\
\text { endolita di plastik } \\
\text { tersebut }\end{array}$ & $\begin{array}{l}\text { 1. Dapat menggunakan alat } \\
\text { press vaccum plastik dan } \\
\text { alat press plastik } \\
\text { 2. Menngunakan plastik } \\
\text { khusus dengan terdapat } \\
\text { merk endolita }\end{array}$ \\
\hline
\end{tabular}

Untuk membantu peningkatan penjualan selain dari segi varian produk bakso ayam yang bertambah serta kemasan bakso yang sudah menarik maka di tunjang dengan pelatihan vokasi pengolahan daging dan surat keterangan Laik Sehat dari Dinas Kesehatan . Hasil pelatihan dan surat keterangan laik sehat dapat dilihat sebagai berikut: 

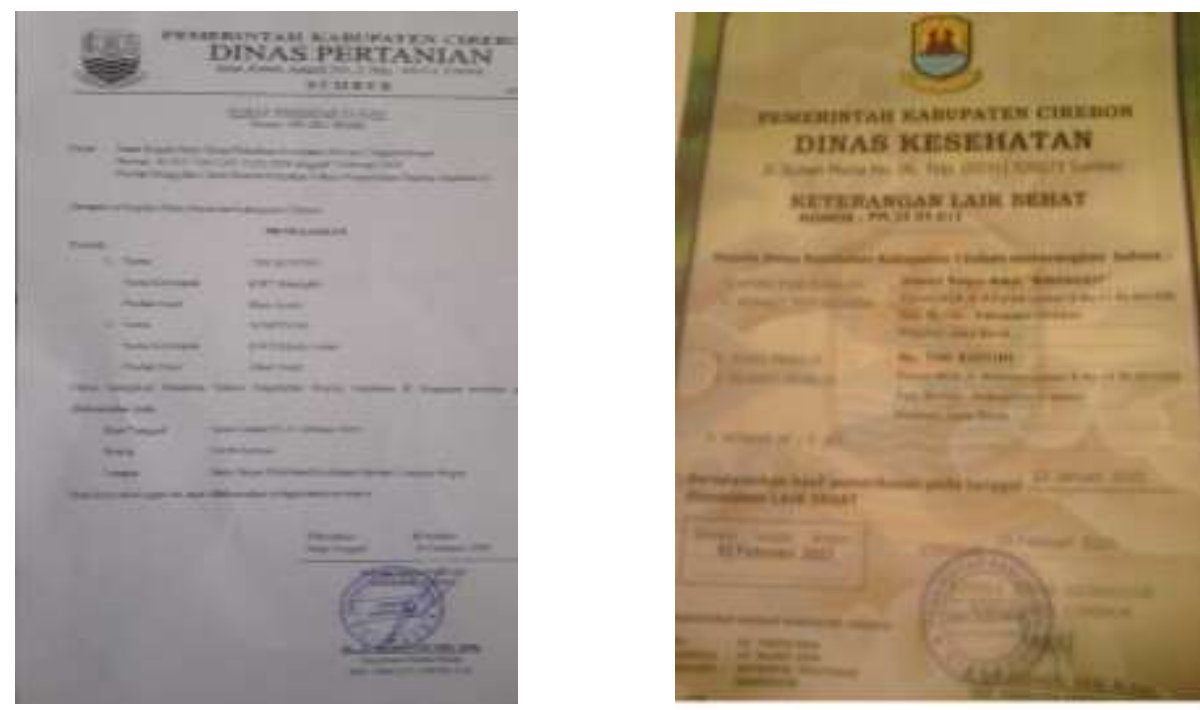

Gambar 9. Surat Keterangan Pelatihan dan Keterangan Laik Sehat

\section{Simpulan dan Rekomendasi}

Simpulan

Pemberian edukasi pengetahuan mengenai bermacam jenis variasi produk bakso ayam dan pelaku usaha mampu membuat varian baru dari bakso ayam yang telah ada yaitu bakso ayam rasa keju dan bakso ayam saos padang dan penggunaan kemasan menggunakan plastik khusus yang diberi merek dengan menggunakan alat press dan alat vacum untuk kemasan, membuat tampilan bakso ayam endolita semakin menarik dan memiliki identitas yang membedakan dengan produsen bakso yang lain

Rekomendasi

Variasi produk bakso ayam dapat ditambah dengan variasi lainnya dengan menggunakan alat bantu yang lebih menunjang serta kemasan dapat ditingkatkan lebih menarik, serta dapat melakukan pengabdian dengan materi yang lebbih dalam atau yang berbeda.

\section{Daftar Pustaka}

A. Azis Said. (2016). Desain Kemasan. Desain Kemasan.

Efnita, T. (2017). PENGARUH VARIASI PRODUK, KUALITAS PELAYANAN, HARGA DAN LOKASI TERHADAP KEPUASAN KONSUMEN PADA WEDDING ORGANIZER. AdBispreneur.

https://doi.org/10.24198/adbispreneur.v2i2.13162

Indiworo, H. E. (2017). PERAN PEREMPUAN DALAM MENINGKATKAN

KINERJA UMKM. EQUILIBRIA PENDIDIKAN : Jurnal Ilmiah Pendidikan Ekonomi. https:// doi.org/10.26877/ep.v1i1.1806

Lena Satlita, A. P. U. D. *. (2017). Gerakan Segoro Amarto: Model Pelembagaan Nilai Untuk Mengatasi Kemiskinan di Kota Yogyakarta. JURNAL SOCIA.

Mufreni, A. N. (2016). Pengaruh Desain Produk, Bentuk Kemasan Dan Bahan

Kemasan Terhadap Minat Beli Konsumen (Studi Kasus Teh Hijau Serbuk 
Tocha). Ekonomi Manajemen.

Ni Wayan Suarmini, Siti Zahrok, D. S. Y. A. (2018). Peluang dan Tantangan Peran

Perempuan. Prosiding SEMATEKSOS 3 "Strategi Pembangunan Nasional Menghadapi Revolusi Industri 4.0."

Sayatman, S., Ramadhani, N., \& Alamin, R. Y. (2018). Pengembangan Desain

Kemasan Produk UMKM Olahan Hasil Laut di Kecamatan Paciran Kab.

Lamongan dalam Rangka Meningkatkan Daya Saing dan Perluasan Pemasaran.

SEWAGATI. https:/ / doi.org/10.12962/j26139960.v2i2.4642

Sedyastuti, K. (2018). Analisis Pemberdayaan UMKM Dan Peningkatan Daya Saing

Dalam Kancah Pasar Global. INOBIS: Jurnal Inovasi Bisnis Dan Manajemen

Indonesia. https:/ / doi.org/10.31842/jurnal-inobis.v2i1.65

Setiawan, H. H. (2017). Penanggulangan Kemiskinan Melalui Pusat Kesejahteraan

Sosial. Sosio Informa.

Totok, M., \& Poerwoko Soebiato. (2019). Pemberdayaan Masyarakat dalam

Perspektif Kebijakan Publik. In Alfabeta. 